\title{
Dexmedetomidine expands monocytic myeloid-derived suppressor cells and promotes tumour metastasis after lung cancer surgery
}

\author{
Xiaosan Su' , Yaodong Fan², Liu Yang ${ }^{1}$, Jie Huang ${ }^{3}$, Fei Qiao ${ }^{3}$, Yu Fang ${ }^{3}$ and Jun Wang ${ }^{3^{*}}$ (ID
}

\begin{abstract}
Background: Dexmedetomidine (DEX) has been reported to promote tumour metastases. However the underlying mechanisms remain unclear. The purpose of this study was to investigate whether DEX promotes tumour metastasis by inducing myeloid-derived suppressor cells (MDSC) in the context of surgery.

Methods: DEX was given to lung cancer patients and its effects on expansion of monocytic MDSC (M-MDSC) were studied in the context of surgery. Spontaneous tumour metastasis was induced in C57BL/6 mice and the effects of DEX on M-MDSC expansion and metastasis formation were assessed.

Results: DEX increased CD $11 \mathrm{~b}^{+} \mathrm{CD} 33^{+} \mathrm{HLA}-\mathrm{DR}{ }^{-} \mathrm{CD} 14^{+} \mathrm{M}-\mathrm{MDSC}$ in lung cancer patients after thoractomy. DEXinduced M-MDSC, in addition to have immunosuppressive activity, were more efficient in producing VEGF. Expansion of M-MDSC by DEX involved $\mathrm{a}_{2}$-adrenergic receptor. Using an experimental tumour metastasis mouse model, we demonstrated that the numbers of metastases on lung surface and CD11 b+ Ly6C $C^{\text {high }}$ Ly $6 \mathrm{G}^{-}$M-MDSC during postoperative period were enhanced in DEX-treated mice. Promotion of tumour metastasis by DEX-induced M-MDSC involved VEGF, a key factor for tumour angiogenesis.

Conclusions: DEX induces the proliferation of M-MDSC during postoperative period in lung cancer patients and this cell population is qualified with potent proangiogenic ability. Treatment of mice with DEX expands M-MDSC and promotes tumour metastasis through the increasing production of VEGF.
\end{abstract}

Keywords: Dexmedetomidine, Myeloid-derived suppressor cells, Lung cancer, Metastasis, Perioperative care

\section{Background}

Dexmedetomidine (DEX) is a highly selective $\alpha_{2}$ adrenergic receptor $\left(\alpha_{2}-\mathrm{AR}\right)$ agonist with various effects on the central nervous system (CNS), including sedation, analgesia and anaesthetic-sparing effects [1]. Current indications have been expanded to include perioperative and procedural sedation [2]. Based on the effects of DEX on sympathetic and immunoregulatory, one can assume beneficial effects in the perioperative period of cancer patients. However, in vitro experiments have

\footnotetext{
*Correspondence: junwangemail@126.com

${ }^{3}$ Department of Anesthesiology, First Affiliated Hospital of Kunming Medical University, 295 Xi Chang Road, Kunming 650032, Yunnan,

People's Republic of China

Full list of author information is available at the end of the article
}

demonstrated that DEX promoted cancer cell survival and proliferation, and in vivo studies have showed promotive effect of DEX on tumour progression [3, 4]. Lavon et al. recently reported that DEX significantly promoted the tumour cell retention and the growth of metastases in rodent models in the context of surgery [5]. These findings call for mechanism studies to understand the deleterious effects of DEX.

Myeloid-derived suppressor cells (MDSC) are characterized by their myeloid origin, immature state, and most importantly by their potent ability to suppress immune responses, especially $\mathrm{T}$ cell proliferation and cytokine production [6]. MDSC consist of two subsets: granulocytic MDSC (G-MDSC) and monocytic MDSC (M-MDSC) [7]. G-MDSC are phenotypically and morphologically similar to neutrophils, whereas M-MDSC 
are similar to monocytes [8]. These cells represent a pathologic state of activation of monocytes and relatively immature neutrophils [9]. These cells are rare in steady-state conditions, but they accumulate abundantly during different pathologies and exert beneficial or deleterious effects to their progression. In recent years, MDSC are implicated in the promotion of tumour metastases by participating in the formation of premetastatic niches, promoting cell invasion and angiogenesis [10]. Our recent studies highlight an emerging role for MDSC in tumour metastasis that M-MDSC accumulate in lung cancer patients undergoing tumour resection and correlates with postoperative tumour metastasis $[11,12]$. While the immunomodulating effects of DEX in cancer have been studied in depth, our understanding of their relevance for MDSC has not been assessed.

Since DEX is commonly used in intraoperative period of cancer patients, the facts that short-term perioperative interventions may affect long-term outcomes, together with causal findings from animal experiments, suggest that the perioperative period has a critical impact on cancer metastasis, and through it determines long-term outcomes [13]. This study aims to investigate the influences of the short-term use of clinically relevant doses of DEX on the progression of cancer metastases in the context of surgery and relevant mechanisms. Specifically, we hypothesized that DEX could promote metastasis through expanding M-MDSC during postoperative period.

\section{Subjects and methods \\ Patients' enrollment}

A total of 103 adult lung cancer patients were prospectively enrolled at the First Affiliated Hospital of Kunming Medical University between July 2014 and July 2016, including 51 cases in the control group (Ctrl) and 52 cases in the dexmedetomidine (DEX) (Hengrui Medicine Co. Ltd, Nanjing, China) treatment group (see Table 1 for
Patients' characteristics). Patients received DEX pre- and intra-operatively with a median consumption of $122 \mu \mathrm{g}$ (118-146 $\mu \mathrm{g})$ using a microinfusion pump. Those who had palliative surgery or secondary malignancies were excluded from the analysis. Ethics Committee approval was obtained from the Internal Review Board of Kunming Medical University and a written informed consent was obtained in accordance with the declaration of Helsinki. Clinical data were collected from patient records and peripheral blood was drawn at preoperation $\left(\mathrm{T}_{0}\right)$ and on postoperative day 1,3 and 7 (depicted as $T_{1}, T_{2}$ and $\mathrm{T}_{3}$ ). Intraoperative anesthetic care of the patients comprised volatile-opioid general anesthesia.

\section{Tumour cell line and mice}

Mouse lewis lung carcinoma (LLC, $\mathrm{H}-2^{\text {b }}$ ) cells were cultured in RPMI 1640 medium (Gibco-BRL, Carlsbad, CA) supplemented with $10 \%$ fetal calf serum, $30 \mu \mathrm{g} / \mathrm{mL}$ gentamicin, and $0.2 \%$ sodium bicarbonate. Inbred female C57BL/6 mice (B6, H-2 ${ }^{\mathrm{b}}$ ) (8-10 weeks) were purchased from the Experimental Animal Institute of Peking Union Medical College.

\section{Flow cytometry analysis and cell sorting}

To determine the frequency and phenotype of MDSC in peripheral blood mononuclear cells (PBMC) from lung cancer patients, flow cytometry (FCM) analysis was done using the following fluorescein-conjugated mouse antihuman monoclonal antibodies (mAb): FITC-CD11b (clone ICRF44), PE-Cy7-CD14 (clone M5E2), PE-CD33 (clone WM53) and PE-Cy5-HLA-DR (clone G46-6) (BD Pharmingen, San Diego, CA). Suspensions of lung cells from mice were prepared using an enzyme digestion method. Briefly, lungs of mice were perfused with 0.02\% EDTA-PBS to wash blood vessels and incubated in RPMI 1640 medium containing collagenase/DNase I, and cell suspensions were washed. Lung cells and peripheral blood collected through tail vein were stained

Table 1 Patients' characteristics

\begin{tabular}{llll}
\hline Clinicopathologic characteristics & Ctrl $(\mathbf{n = 5 1 )}$ & DEX $(\mathbf{n}=\mathbf{5 2})$ & $\boldsymbol{P}$ value \\
\hline Age: median (minimum-maximum), years & $59(48-67)$ & $63(51-74)$ & $0.615^{\mathrm{a}}$ \\
Gender: female/male & $21 / 30$ & $23 / 29$ & $0.754^{\mathrm{b}}$ \\
Histology: adenocarcinoma/squamous cell carcinoma & $38 / 13$ & $44 / 8$ & $0.203^{\mathrm{b}}$ \\
TNM stage: II/II & $23 / 28$ & $18 / 34$ & $0.277^{\mathrm{b}}$ \\
Vascular invasion: present/absent & $19 / 32$ & $12 / 40$ & $0.117^{\mathrm{b}}$ \\
Tumor size: $<3 \mathrm{~cm} />3 \mathrm{~cm}$ & $25 / 26$ & $30 / 22$ & $0.378^{\mathrm{b}}$ \\
Tumor number: single/multiple & $33 / 18$ & $40 / 12$ & $0.172^{\mathrm{b}}$ \\
Anesthesia duration: median (minimum-maximum), minutes & $226(168-422)$ & $238(184-454)$ & $0.475^{\mathrm{a}}$ \\
\hline
\end{tabular}

\footnotetext{
${ }^{a}$ Mann-Whitney $U$ test
}

b Pearson's Chi square test 
with different combinations of the following rat antimouse mAbs: FITC-CD11b (clone M1/70.15), PE-CD45 (clone 30-F11), PE-Cy5-Ly-6G (clone 1A8), PE-Cy7-Ly6C (clone HK1.4) (BD Pharmingen). FCM was done on Beckman Coulter FC500 (San Jose, CA) and FCM data was analyzed using CXP software (Beckman Coulter). The percentage of $\mathrm{CD} 11 \mathrm{~b}^{+} \mathrm{CD} 33^{+} \mathrm{HLA}^{-\mathrm{DR}}{ }^{-} \mathrm{CD} 14^{-}$and

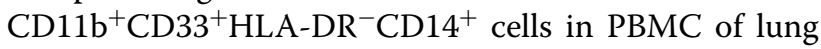
cancer patients was calculated according the formula: $=\%$

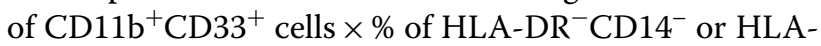
$\mathrm{DR}^{-} \mathrm{CD} 14^{+}$cells in PBMC. FCM analysis of the expression of $\alpha_{2}$-AR on either human or mouse MDSC was performed using Biotin-conjugated mouse anti-human/ mouse $\alpha_{2}$-AR mAb (clone S330A-51) (Novus Biologicals, Littleton, CO) and Streptavidin-BD Horizon ${ }^{\mathrm{TM}}$ PE-CF594 (BD Pharmingen).

Human PBMC were isolated from freshly heparinized peripheral blood from lung cancer patients by standard Ficoll density gradient centrifugation (Haoyang Biological Manufacture Co. Ltd, Tianjin, China). Isolation of $\mathrm{CD} 11 \mathrm{~b}^{+} \mathrm{CD} 33^{+} \mathrm{HLA}-\mathrm{DR}^{-}$,

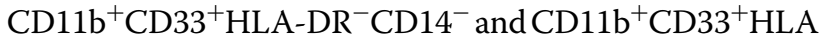
$-\mathrm{DR}^{-} \mathrm{CD} 14^{+}$cells was performed on FACSVantage SE cell sorter (Becton-Dickinson, Franklin Lakes, NJ). For cell sorting in mice, suspensions of lung cells were stained with fluorescein-conjugated rat anti-mouse $\mathrm{CD} 11 \mathrm{~b}$, Ly6C and Ly6G mAb. Isolation of CD11b ${ }^{+} \mathrm{Ly}_{6} \mathrm{C}^{\text {low }} \mathrm{Ly}_{6 \mathrm{G}}{ }^{+}$(G-MDSC) and $\mathrm{CD} 11 \mathrm{~b}^{+} \mathrm{Ly}_{6 \mathrm{C}^{\text {high }}} \mathrm{Ly}_{6 \mathrm{G}^{-}}$(M-MDSC) was performed on FACSVantage SE cell sorter.

\section{Immunoassay for cytokines}

The serum concentration of VEGF in lung cancer patients was detected with a commercial enzyme-linked immunosorbent assay (ELISA) kit (RayBiotech, Inc. Norcross, $\mathrm{GA}$ ) according to the manufacturer's instructions.

\section{MDSC suppression assay}

The suppressive function of MDSC was assessed based on their ability to inhibit CD3-induced $\mathrm{T}$ cell activation. $\mathrm{CD}^{+}$cells were isolated from PBMC of lung cancer patients preoperatively using anti-CD3 magnetic beads (Miltenyi Biotec, Bergisch Gladbach, Germany) and plated at $2 \times 10^{5}$ cells/well in $1 \mu \mathrm{g} / \mathrm{mL}$ of anti-CD3 Abs (muromonabCD3, Janssen Pharmaceutica, Titusville,

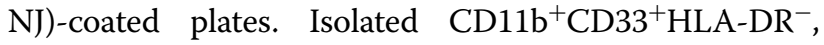

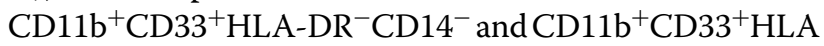
$-\mathrm{DR}^{-} \mathrm{CD} 14^{+}$cells $\left(1 \times 10^{5}\right.$ cells/well $)$ from the same lung cancer patient during perioperative period were added to the wells. Cell proliferation was determined $72 \mathrm{~h}$ later after incubating with ${ }^{3} \mathrm{H}$-thymidine for the last $16 \mathrm{~h}$.

\section{Reverse transcription quantitative PCR}

MDSC were isolated from lung cancer patients during perioperative period and total RNA was extracted using TaKaRa RNAiso Reagent (Takara Bio Inc. Otsu, Japan) according to the manufacturer's instructions. A reverse transcription-polymerase chain reaction (RT$\mathrm{PCR}$ ) procedure was used to determine relative quantities of mRNA (One-step RT-PCR kit, Qiagen). The primers for all genes tested were synthesized by Invitrogen: VEGF 5'-CATTGGAGCCTTGCCTTG-3' (sense) and $5^{\prime}$-TTCGTGGGGTTTCTGGTCT- ${ }^{\prime}$ (antisense), GAPDH $\quad 5^{\prime}$-AGCCACATCGCTCAGACAC-3' (sense) and $5^{\prime}$-GCCCAATACGACCAAATCC- ${ }^{\prime}$ (antisense). For quantitative real-time PCR, cDNA $(2 \mu \mathrm{L})$ reverse transcribed from total RNA was amplified by real-time PCR with 1 SYBR Green Universal PCR Mastermix (BioRad). Each sample was analyzed in duplicate with the IQ-Cycler (Bio-Rad) and the normalized signal level was calculated based on the ratio to the respective GAPDH housekeeping signal.

To assess the relative mRNA expression of VEGF in mice, $\mathrm{CD}_{11 b^{+} \mathrm{Ly} \mathrm{C}^{\text {low }} \mathrm{Ly} 6 \mathrm{G}^{+}}$(G-MDSC) and

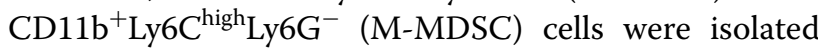
from lungs of PBS (Ctrl), dexmedetomidine (DEX), or dexmedetomidine and yohimbine $(\mathrm{DEX}+\mathrm{YOH})$-treated mice and total RNA was extracted using TaKaRa RNAiso Reagent according to the manufacturer's instructions. A RT-PCR procedure was used to determine relative quantities of mRNA. The primers for all genes tested were synthesized by Invitrogen: VEGF 5'-GTACTTGCAGAT GTGACAAGCCA-3' (forward) and 5'-GGTGACATG GTTAATCGGTCTTT-3' (reverse); GAPDH $5^{\prime}$-CCG GTGCTGAGTATGTCGT-3' (forward) and 5'-CCTTTT GGCTCCACCCTTC-3' (reverse). Each sample was analyzed in duplicate with the IQ-Cycler (Bio-Rad) and the normalized signal level was calculated based on the ratio to the respective GAPDH housekeeping signal.

\section{DEX tunes the differentiation of MDSC in vitro}

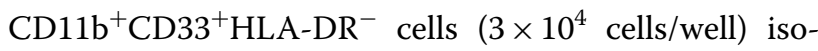
lated from peripheral blood of lung cancer patients $24 \mathrm{~h}$ after surgery using fluorescence-activated cell sorting (FACS) were cultured in RPMI 1640 medium, alone or cocultured with DEX $(2.5 \mathrm{ng} / \mathrm{mL})$, yohimbine ( $\mathrm{YOH}$, an $\alpha_{2}$-adrenergic antagonist) (2.5 ng/ $\mathrm{mL}$, see Additional file 1: Figure S1 for dose) (SigmaAldrich, St. Louis, MO), or DEX $(2.5 \mathrm{ng} / \mathrm{mL})$ and $\mathrm{YOH}(2.5 \mathrm{ng} / \mathrm{mL})(\mathrm{DEX}+\mathrm{YOH})$. A total of 24,48 and $72 \mathrm{~h}$ after culture, floating cells were gently collected and numerated using a TC10 automated cell counter (Bio-Rad). The percentage of $\mathrm{CD}_{11} \mathrm{~b}^{+} \mathrm{CD} 33^{+} \mathrm{HLA}$

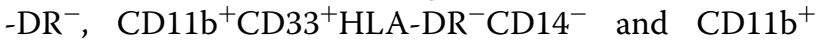


$\mathrm{CD}_{3}{ }^{+} \mathrm{HLA}^{-} \mathrm{DR}^{-} \mathrm{CD} 14^{+}$cells was analyzed by FCM and the absolute number of these cells was calculated according to the following formula:

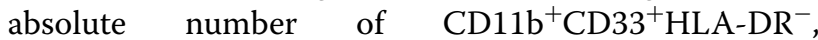

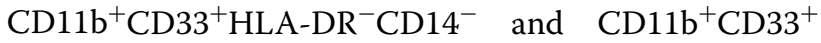
HLA-DR ${ }^{-} \mathrm{CD}_{14}{ }^{+}$cells $=$total number of cells harvested from each well $\times$ percent of $\mathrm{CD} 11 \mathrm{~b}^{+} \mathrm{CD} 33^{+} \mathrm{HLA}-\mathrm{DR}^{-}$,

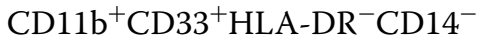

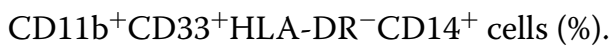

\section{Experimental tumour metastasis model and surgical operation procedure}

LLC spontaneous pulmonary metastasis experiments were performed as described previously [14]. Briefly, $1 \times 10^{6}$ LLC cells in $0.1 \mathrm{~mL}$ of PBS were injected s.c. into the dorsa of C57BL/6 mice. When tumours were $\sim 1500 \mathrm{~mm}^{3}$ in size, 14 days after LLC inoculation, the mice were randomly divided into three groups and treated with PBS (Ctrl group), dexmedetomidine (DEX group), or dexmedetomidine and yohimbine $(2 \mathrm{mg} / \mathrm{kg}$ ) (DEX $+\mathrm{YOH}$ group) [5]. Then the mice immediately underwent surgical removal of the tumor. To simulate the DEX clinical kinetics and effects, the dose $10 \mu \mathrm{g} / \mathrm{kg} \mathrm{h}$ was chosen to reach an average plasma level of $1.5 \mathrm{ng} / \mathrm{mL}$ [5]. The DEX was administered using a slow release vehicle, which prevents initial high plasma levels and maintains prolonged exposure to the drugs. Mice received DEX pre- and intra-operatively with a median consumption of $0.5 \mu \mathrm{g}(0.46-0.62 \mu \mathrm{g})$. All the mice in three groups were intraperitoneal injected with $0.8 \mathrm{mg} / \mathrm{kg} /$ mouse sodium pentobarbital (Sigma-Aldrich) for anesthesia. The day of tumor resection was designated as Day 0 . Ten days after tumor resection, the mice were sacrificed, and their lungs were removed, and visible surface metastases were counted. The survival time of rest mice were continuously monitored for at least 60 days. All animal experiments were performed according to the guidelines and protocols approved by the Institutional Animal Care and Use Committee at Kunming Medical University.

\section{Immunohistochemistry}

Tumour sections from mouse pulmonary metastatic nodules were incubated with rat anti-mouse CD31 mAb (clone MEC 13.3) (BD Pharmingen). A biotinylated rabbit anti-rat 2nd antibody was applied, followed by incubation with streptavidin-conjugated horseradish peroxidase (HRP). Peroxidase activity was localized with diaminobenzi dine (Shangon biotech Co. Ltd, Shanghai, China).

\section{Statistical analysis}

GraphPad Prism 5.0 (La Jolla, CA) was used for data analysis. Results were presented as mean \pm standard deviation (SD). Mann-Whitney U test and Pearson's
Chi square test were performed to evaluate the patient's characteristics between Ctrl and DEX group. Unpaired two-tailed Student's $t$-test was used to compare means between 2 groups. For comparison of individual time points, ANOVA was used for the comparisons among 3 or more groups. For the analysis of survival, log-rank Kaplan-Meier analysis was used. Differences were considered significant when $P<0.05$.

\section{Results}

DEX expands M-MDSC in lung cancer patients after surgery In human, MDSC are characterized by the cell surface expression of integrin CD11b, sialic acid binding lectin CD33 and low expression of HLA-DR [15]. Based on these surface markers, we found that while

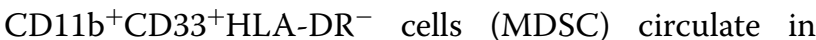
lung cancer patients at baseline (preoperation, $\mathrm{T}_{0}$ ), the

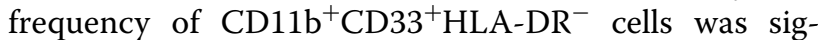
nificantly increased on postoperative day 1,3 and 7 ( $\mathrm{T}_{1}, \mathrm{~T}_{2}$ and $\mathrm{T}_{3}$, respectively) (Fig. $1 \mathrm{a}, \mathrm{b}$ ). When lung cancer patients were treated with DEX, we found that

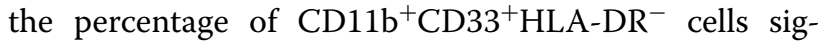
nificantly increased as compared with patients in Ctrl group on postoperative days 1, 3 and 7 (Fig. 1b). $\mathrm{CD}_{11 \mathrm{~b}}{ }^{+} \mathrm{CD}_{3}{ }^{+}{ }^{\mathrm{HLA}} \mathrm{L}-\mathrm{DR}{ }^{-}$cells can be further divided into two subpopulations of cells expressing $\mathrm{CD} 14^{-}$or $\mathrm{CD}_{14}{ }^{+}$(Fig. 1a). No significant differences in the percentage of CD14- MDSC (G-MDSC) were found between Ctrl and DEX group during perioperative period (Fig. 1c). In contrast, the administration of DEX significantly increased the frequency of CD14 ${ }^{+}$MDSC (M-MDSC) on postoperative days 1, 3 and 7 (Fig. 1d). Thus, the administration of DEX promotes the expansion of M-MDSC in lung cancer patients.

\section{DEX-induced M-MDSC exert immunosuppressive and proagiogenic activity}

We next evaluated the capacity of MDSC from DEXtreated patients to suppress $\mathrm{T}$ cell proliferation. In contrast with MDSC isolated from Ctrl group, MDSC in DEX group demonstrated higher level of $\mathrm{T}$ cell suppression (Fig. 2a). There was no difference in the $\mathrm{T}$ cell suppression of G-MDSC between Ctrl and DEX group during perioperative period (Fig. 2b). Although the M-MDSC isolated from either Ctrl or DEX group exerted immunosuppressive function against $\mathrm{T}$ cell proliferation, the M-MDSC in DEX-treated patients was more potent in inhibiting $\mathrm{T}$ cell proliferation on postoperative day 3 and 7 (Fig. 2c).

It has been reported that MDSC release VEGF and mediate tumour angiogenesis [11, 16]. In order to determine whether the administration of DEX was associated with higher level of VEGF, we first detected 


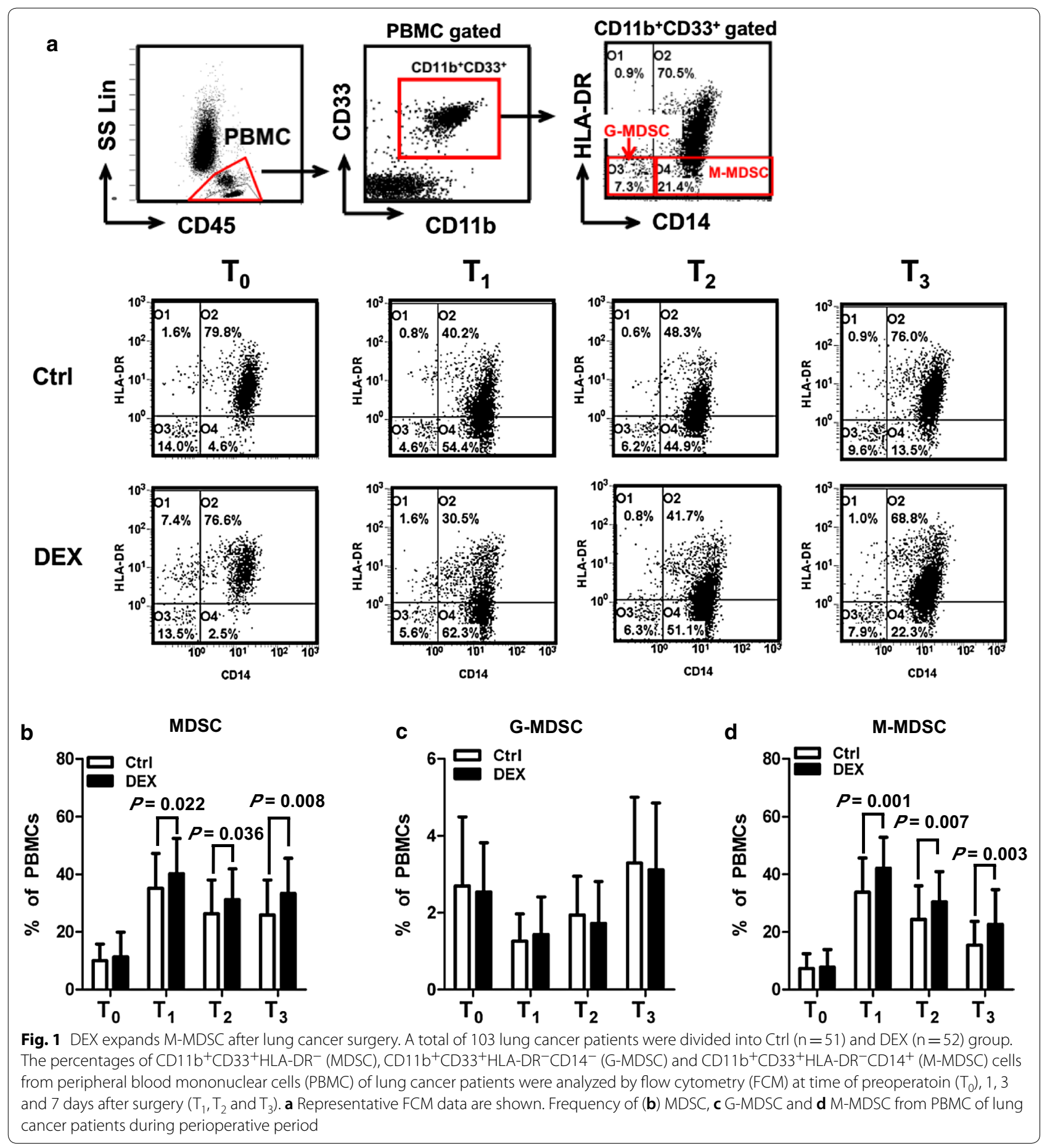

the levels of VEGF in the serum of Ctrl and DEX patients by ELISA. We found that the concentration of VEGF was elevated in serum from DEX-treated lung cancer patients as compared with Ctrl group on postoperative day 3 and 7 (Fig. 2d). The mRNA levels of VEGF were also measured in G-MDSC and M-MDSC.
A similar pattern in mRNA expression level of VEGF was observed in G-MDSC isolated from patients of Ctrl and DEX group. In contrast, M-MDSC from DEXtreated patients had higher mRNA level of VEGF relative to Ctrl group (Fig. 2e, f). 

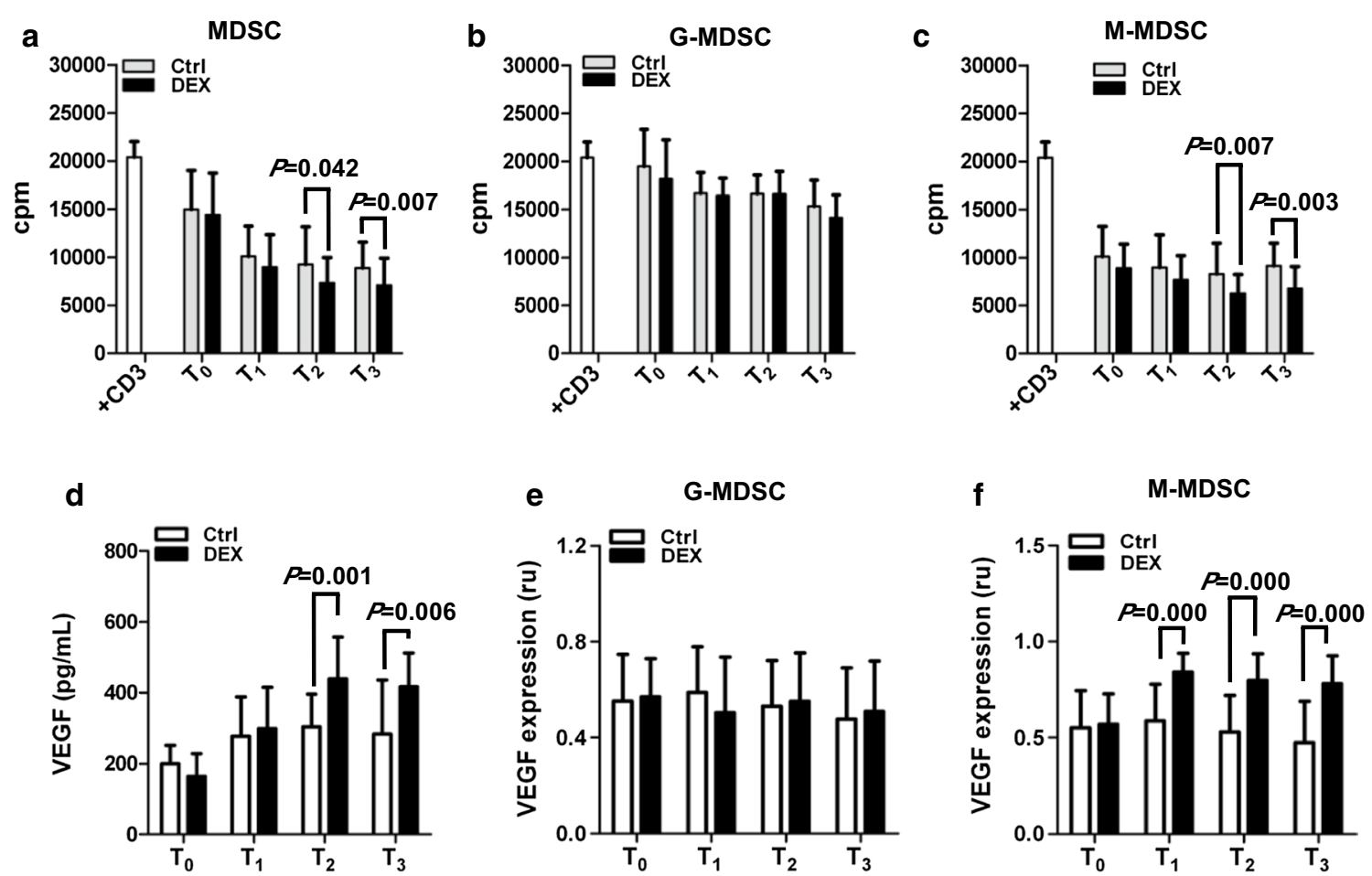

Fig. 2 DEX-induced monocytic MDSC exerts immunosuppressive activity and produces VEGF. CD3 ${ }^{+}$cells were isolated from lung cancer patients $(n=16)$ preoperatively and plated at $2 \times 10^{5}$ cells $/$ well in $1 \mu \mathrm{g} / \mathrm{mL}$ of anti-CD3 Abs-coated plates in the presence of (a) CD1 1 b $\mathrm{b}^{+} \mathrm{CD} 33^{+} \mathrm{HLA}-\mathrm{DR} \mathrm{R}^{-}$ (MDSC), $\mathbf{b}$ CD11 $b^{+} \mathrm{CD}_{3} 3^{+} \mathrm{HLA}-\mathrm{DR}{ }^{-} \mathrm{CD} 14^{+}$(M-MDSC) or $\mathbf{c} \mathrm{CD} 11 \mathrm{~b}^{+} \mathrm{CD}_{3} 3^{+} \mathrm{HLA}-\mathrm{DR}{ }^{-} \mathrm{CD} 14^{-}$(G-MDSC) cells $\left(1 \times 10^{5}\right.$ cells/well) sorted from the same lung cancer patient at time of preoperatoin $\left(T_{0}\right), 1,3$ and 7 days after surgery $\left(T_{1}, T_{2}\right.$ and $\left.T_{3}\right)$. The proliferation of $C D 3^{+}$cells was measured in triplicate by ${ }^{3} \mathrm{H}$-thymidine incorporation. $\mathbf{d}$ Serum concentration of VEGF in lung cancer patients of $\mathrm{Ctrl}(\mathrm{n}=16)$ and DEX $(n=16)$ group during perioperative period was measured with ELISA. e G-MDSC and $\mathbf{f} M$ M-MDSC were isolated from lung cancer patients of Ctrl $(n=16)$ and DEX $(n=16)$ group during perioperative period and the relative mRNA expression of VEGF was analyzed by RT-qPCR. ru: relative units

\section{DEX expands M-MDSC by $a_{2}-A R$ receptor}

To investigate the mechanism behind DEX-mediated expansion of M-MDSC, we checked the expression of $\alpha_{2}$-AR, the cognate receptor for DEX, on MDSC. We found that MDSC constitutively expressed low level of $\alpha_{2}-A R$, and when lung cancer patients were undergone tumour resection, the expression of $\alpha_{2}$-AR on MDSC was elevated (Fig. 3a, b). After tumour resection and DEX administration, lung cancer patients had a significant increase of $\alpha_{2}$-AR on the MDSC and M-MDSC, but not G-MDSC (Fig. 3b-d). Moreover, the levels of $\alpha_{2}$-AR on the MDSC, G-MDSC and M-MDSC from Ctrl patients were similar to the levels seen in DEX-treated patients at the same time point (Fig. 3a-d).

To confirm the in vivo promotion of M-MDSC by DEX, we isolated CD $11 \mathrm{~b}^{+} \mathrm{CD} 33^{+} \mathrm{HLA}^{-\mathrm{DR}}{ }^{-}$cells from lung cancer patients after surgery and performed a series of coculture experiments in vitro. We found that exogenous addition of DEX induced expansion of MDSC and M-MDSC, most consistently and significantly at $12 \mathrm{~h}$ after coculture (Fig. 3e-g). The addition of yohimbine ( $\mathrm{YOH}$, an $\alpha_{2}$-adrenergic antagonist) inhibited the expansion of MDSC and M-MDSC caused by DEX (Fig. 3e and g). Thus, DEX mediates the expansion of M-MDSC by binding to $\alpha_{2}$-AR.

\section{DEX induces M-MDSC and promotes tumour metastasis after surgery}

To assess the possible role of DEX in the prognosis of a tumour-bearing host undergoing tumour resection, C57BL/6 mice were treated with DEX. As showed in Fig. 4a, DEX administration systemically promoted the growth of metastatic lung tumours as quantified by counting metastatic nodules on pulmonary surface in the mice undergone tumour resection. Significant differences in the number of metastasis were found between Ctrl and DEX-treated mice 10 days after tumour resection (Fig. 4b). When DEX was given with $\mathrm{YOH}$, a selective $\alpha_{2}$ $\mathrm{AR}$ antagonist, its effects on pulmonary metastasis were prevented (Fig. 4a, b). In a separate set of experiments, we evaluated whether the treatment of DEX had effects on the survival of mice undergone tumour resection. When the mice show dyspnea, they were euthanized and their lungs were removed. The freshly isolated lungs from Ctrl, 

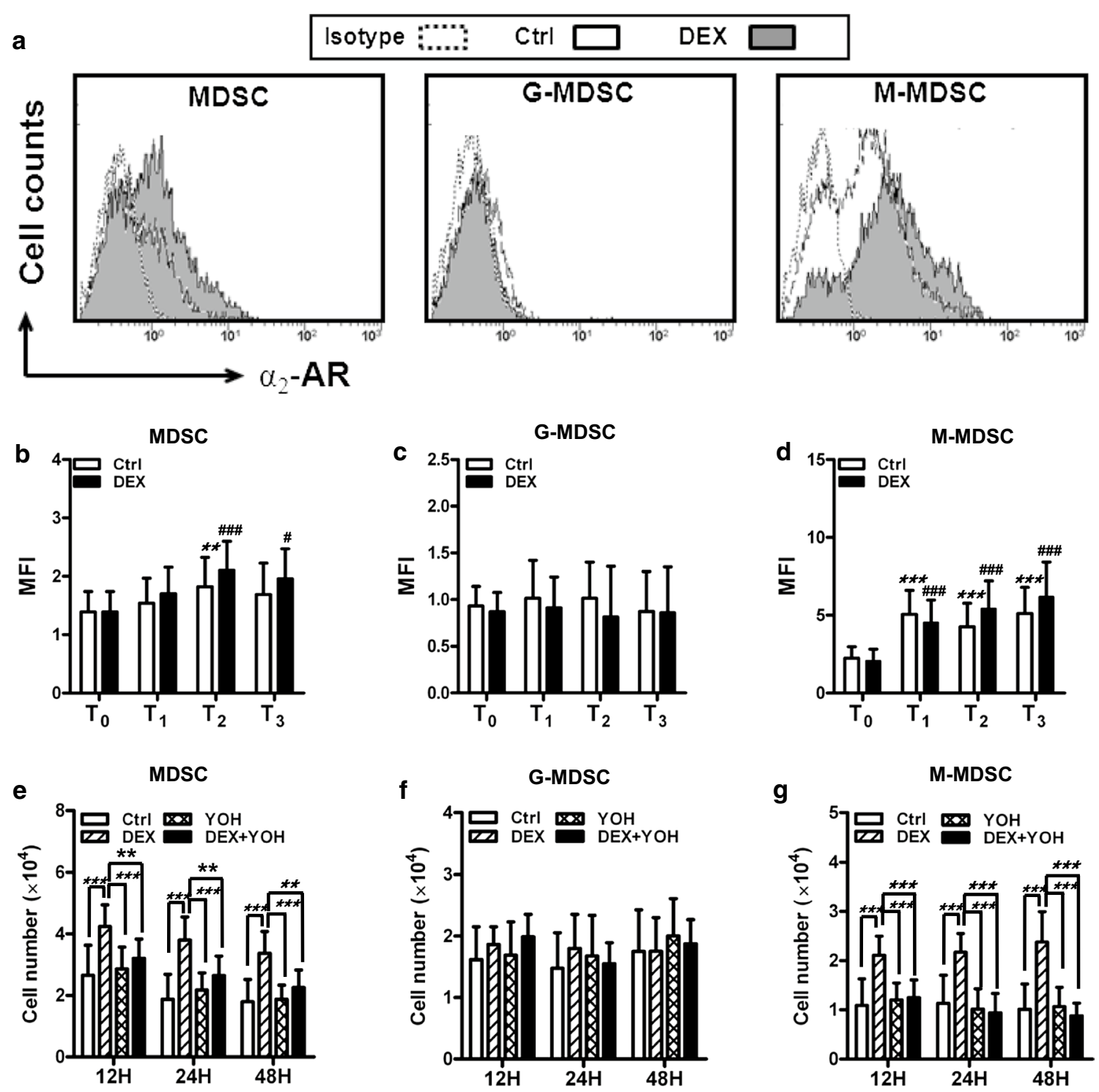

Fig. 3 Expansion of M-MDSC by DEX is mediated via $\mathrm{a}_{2}$-AR. a Expression of $\mathrm{a}_{2}-\mathrm{AR}$ on $\mathrm{CD} 11 \mathrm{~b}^{+} \mathrm{CD} 33^{+} \mathrm{HLA}-\mathrm{DR} \mathrm{R}^{-}$(MDSC),

$\mathrm{CD} 11 \mathrm{~b}^{+} \mathrm{CD} 33^{+} \mathrm{HLA}-\mathrm{DR}{ }^{-} \mathrm{CD} 14^{-}$(G-MDSC) and CD11 $\mathrm{b}^{+} \mathrm{CD} 33^{+} \mathrm{HLA}-\mathrm{DR}{ }^{-} \mathrm{CD} 14^{+}$(M-MDSC) was analyzed in peripheral blood mononuclear cells (PBMC) of lung cancer patients at time of preoperatoin $\left(T_{0}\right), 1,3$ and 7 days after surgery $\left(T_{1}, T_{2}\right.$ and $\left.T_{3}\right)$ by flow cytometry $(F C M)$. Representative FCM data of $a_{2}$-AR on MDSC, G-MDSC and M-MDSC on days 3 after tumor resection are shown. $\mathbf{b}$ - $\mathbf{d}$ Mean fluorescent intensity (MFI) of $\mathbf{a}_{2}$-AR on $\mathbf{b}$ MDSC, c G-MDSC and $\mathbf{d}$ M-MDSC was assessed. ${ }^{* *} P<0.01$ and ${ }^{* * *} P<0.001$ as compared with $\mathrm{T}_{0}$ in Ctrl group; ${ }^{\#} P<0.05^{\# \# \#} P<0.001$ as compared with $\mathrm{T}_{0}$ in DEX group. $\mathbf{e}-\mathbf{g}$ CD $11 \mathrm{~b}^{+} \mathrm{CD} 33^{+} \mathrm{HLA}-\mathrm{DR}^{-}$cells $\left(3 \times 10^{4}\right.$ cells/well) isolated from lung cancer patients $(\mathrm{n}=16) 24 \mathrm{~h}$ after surgery were cocultured with dexmedetomidine (DEX) $(2.5 \mathrm{ng} / \mathrm{mL})$, yohimbine ( $\mathrm{YOH}$, an a $\mathrm{a}_{2}$-adrenergic antagonist) $(2.5 \mathrm{ng} / \mathrm{mL})$, or dexmedetomidine $(2.5 \mathrm{ng} / \mathrm{mL})$ and yohimbine $(2.5 \mathrm{ng} / \mathrm{mL})(\mathrm{DEX}+\mathrm{YOH})$. Twelve, twenty-four and forty-eight hours after coculture, floating cells were gently collected and numerated using an automated cell counter. The percentage of MDSC, G-MDSC or M-MDSC was analyzed by FCM and the absolute number of these cells was calculated. ${ }^{*} P<0.05,{ }^{* *} P<0.01,{ }^{* * *} P<0.001$

DEX and "DEX $+\mathrm{YOH}$ " group had some replacement of the normal lung tissue by large metastatic nodules (Additional file 2: Figure S2A). All DEX-treated mice succumbed to the tumour metastasis within 2 months after the start of the tumour resection and DEX treatment. In contrast, $50 \%$ mice in Ctrl and "DEX $+\mathrm{YOH}$ " group were still alive at that time point (Fig. 4c). The lungs of survived mice from $\mathrm{Ctrl}$ and "DEX $+\mathrm{YOH}$ " group had less metastatic nodules (Additional file 2: Figure S2B).

We then asked whether the induction and proliferation of M-MDSC could be affected following DEX administration. Mouse granulocytic and 

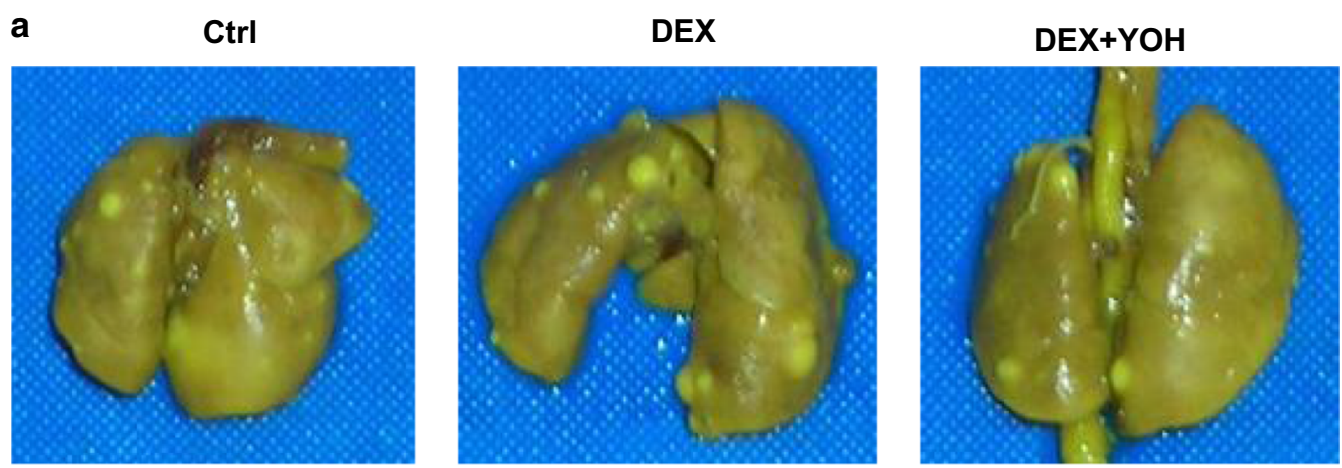

b

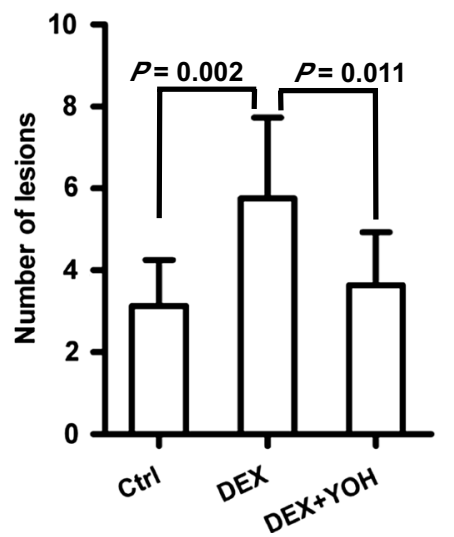

C

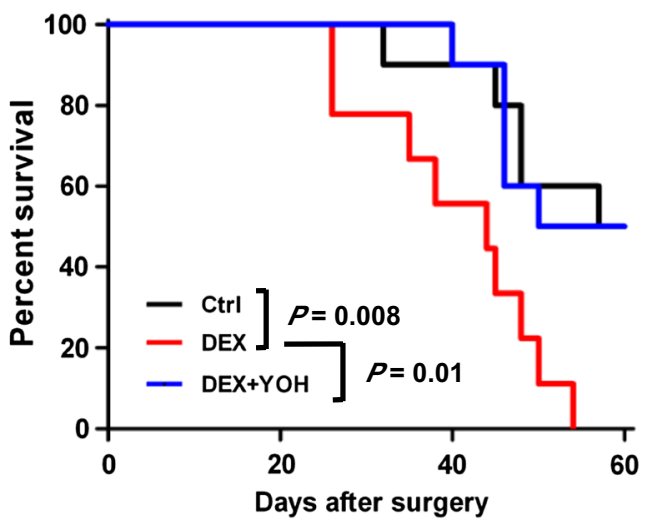

Fig. 4 DEX promotes tumour metastases in mice exposed to tumour excision. $1 \times 10^{6}$ LLC cells were injected s.C. into the dorsa of C57BL/6 mice. When tumours were $\sim 1500 \mathrm{~mm}^{3}$ in size, 14 days after LLC inoculation, the mice were randomly divided into three groups and treated with PBS (Ctrl group), dexmedetomidine (DEX group), or dexmedetomidine and yohimbine (DEX $+\mathrm{YOH}$ group). Then the mice immediately underwent surgical removal of the tumor. All mice were sacrificed 10 days after surgery and the numbers of metastases on the lung surface were counted. a Typical examples of lung tissue. b The number of tumour lesions per lung (six mice per group). c Survival of mice in Ctrl, DEX and DEX + YOH group (ten mice per group). Data presented are representative of three replicated experiments

monocytic MDSC are defined as CD11b ${ }^{+} \mathrm{Ly}_{6 C^{\text {low }}} \mathrm{Ly}_{6 \mathrm{G}}{ }^{+}$ (G-MDSC) and CD11b ${ }^{+} \mathrm{Ly}_{6} \mathrm{C}^{\text {high }} \mathrm{Ly}^{-} \mathrm{G}^{-}$(M-MDSC) (Fig. 5a) $[8,9]$. Based on these cell surface markers, we found that after DEX treatment, mice had a significant increase of M-MDSC, but not G-MDSC, in their peripheral blood and lungs (Fig. 5b). The administration of $\mathrm{YOH}$ abrogated the expansion of

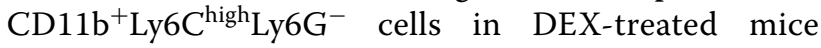
(Fig. 5a, b). Taken together, these results suggested that DEX expanded M-MDSC after surgical manipulation in tumour-bearing mice and promoted tumour metastasis. We also analyzed the expression of $\alpha_{2}$-AR on the mouse MDSC. There was a significant increase of $\alpha_{2}$ AR on the MDSC and M-MDSC of lungs of mice in Ctrl, DEX and "DEX + YOH" group after tumour resection (Additional file 3: Figure S3A, B). No significant differences in the expression of $\alpha_{2}$-AR on G-MDSC were found in Ctrl, DEX and "DEX $+\mathrm{YOH}^{\mathrm{O}}$ " group during perioperative period (Additional file 3: Figure $\mathrm{S} 3 \mathrm{C})$.

\section{DEX induces VEGF in M-MDSC and promotes tumour angiogenesis}

To investigate whether increased vascularity could explain the increased tumour metastssis in the DEXtreated mice, we stained tumour samples with antiCD31 antibody. Significant higher blood vessel density was observed in metastatic nodules derived from DEX-treated mice after surgery than those from Ctrl and "DEX $+\mathrm{YOH}^{-}$-treated mice, with an average of $(6.63 \pm 1.80), \quad(15.88 \pm 3.37)$ and $(8.63 \pm 1.58)$ respectively (Fig. 6a, b). To evaluate the proagiogeneic activity of G-MDSC and M-MDSC, we examined the mRNA levels of VEGF in Ctrl, DEX- and "DEX + $\mathrm{YOH}^{-}$ treated mice (Fig. 6c). No significant differences in the mRNA expression of VEGF in the G-MDSC were found between Ctrl, DEX- and "DEX+YOH"-treated 


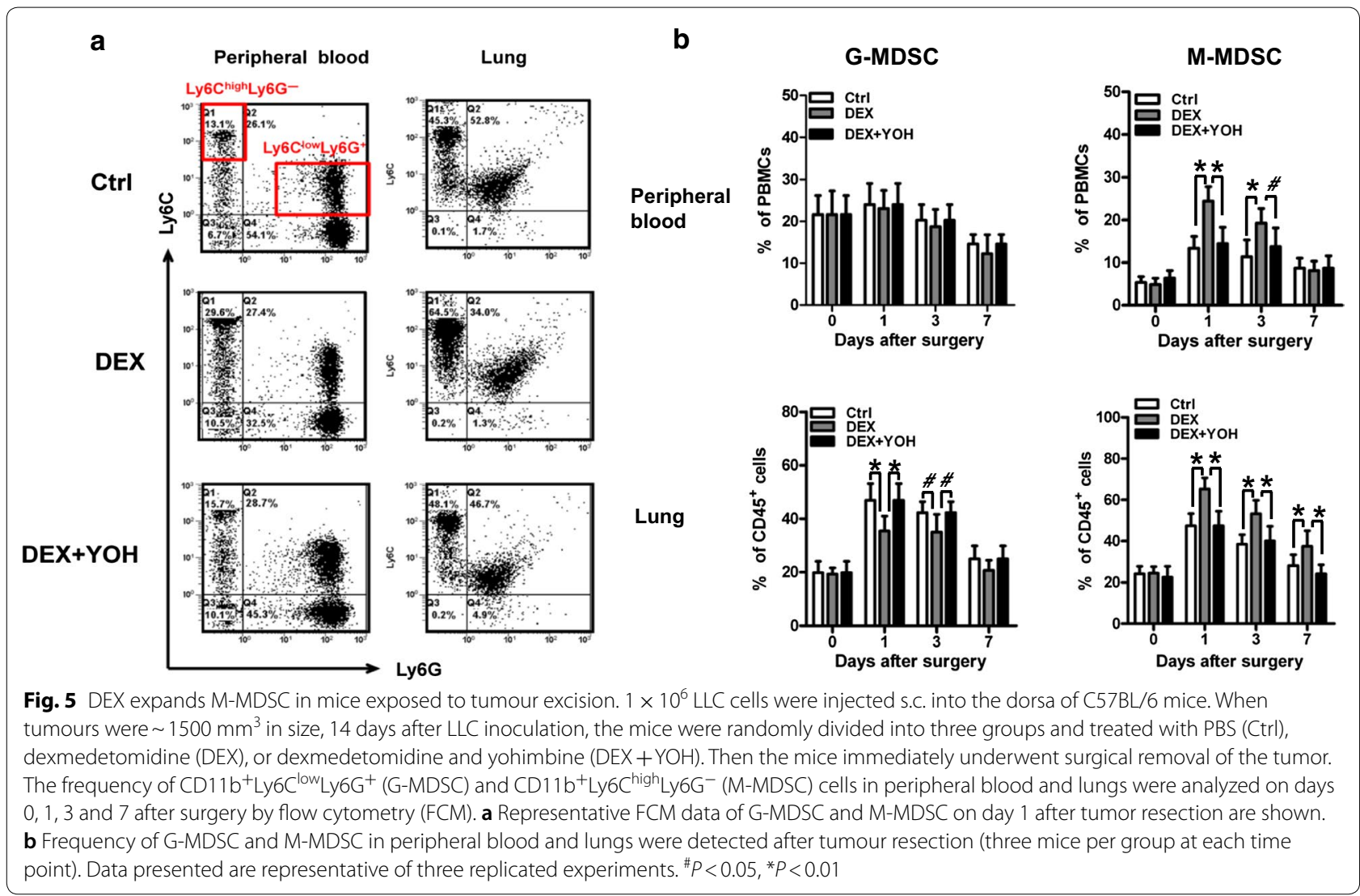

mice during perioperative period (Fig. 6d). However,

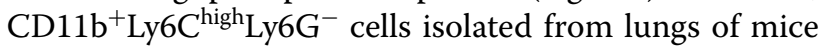
treated with DEX produced higher mRNA level of VEGF as compared with Ctrl and "DEX $+\mathrm{YOH}^{-}$-treated mice (Fig. 6e).

\section{Discussion}

This study focused on the effect of DEX on cancer metastasis in the context of surgery, similar to the perioperative setting of DEX used in cancer patients [17]. We found that after lung cancer surgery the peripheral blood of DEX-treated patients was of higher accumulation of monocytic MDSC and consequently these cells were more efficient in suppressing $\mathrm{T}$ cell proliferation and producing proangiogenic factor VEGF. These modulation effects were dependent on the expression of $\alpha_{2}$ AR on M-MDSC. We also investigated the influence of surgical resection on the generation of M-MDSC and the growth of tumour metastasis using an experimental mouse tumour model, and demonstrated that the numbers of metastases on lung surface and M-MDSC during postoperative period were increased in DEX-treated mice. Taken together, these data suggest that DEXinduced M-MDSC during postoperative period were qualified with potent proangiogenic and tumour promotive activity.

Following a surgery, cellular immunity remains suppressed for several days with decrease in circulating levels of cytotoxic $\mathrm{T}$ lymphocytes, dendritic cells, natural killer cells and helper T cells (Th) $[13,18,19]$. The magnitude of this immune suppression is proportional to the degree of surgical manipulation [20]. Recent experimental and clinical evidences suggest that DEX has been associated with reduced inflammatory cytokine release, modulation of inflammatory transcription factors, oxidative stress and inflammatory cells [21]. A randomized controlled trial in gastric cancer patients who had gastrectomies indicates that DEX, given intraoperatively, has potent immunomodulatory properties that are observed as improvement in the Th1/Th2 ratio and reduction in IL-6 and tumor necrosis factor (TNF) [22]. Similar results were reported in other randomized controlled trials that DEX alleviates the reduction of cellular immunity, thereby ameliorating the impaired immune functions in patients who had mastectomy or radical surgery of colon carcinoma [23-25]. In addition to cell-mediated immunity, the immunosuppressive components in peripheral and premetastatic tissue have been showed potent tumour-promoting activity [26]. 
a

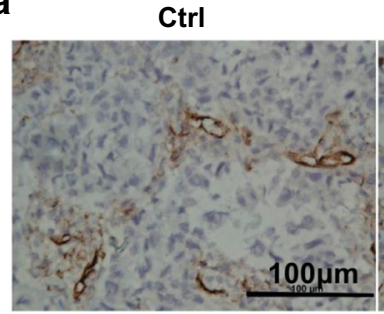

c

c

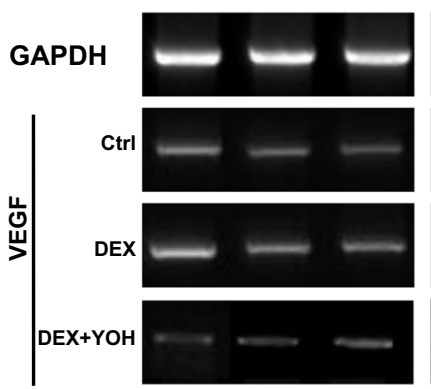

M-MDSC

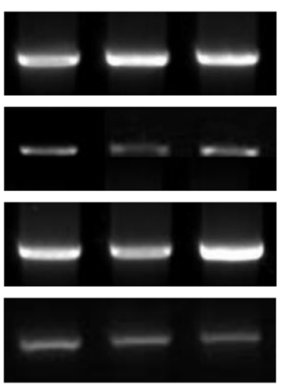

d

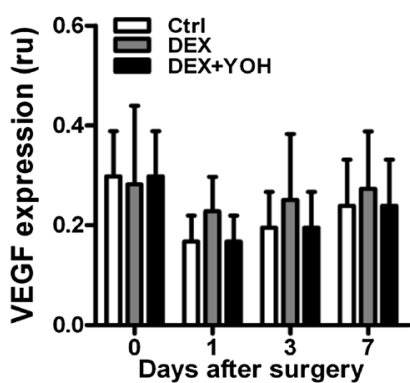

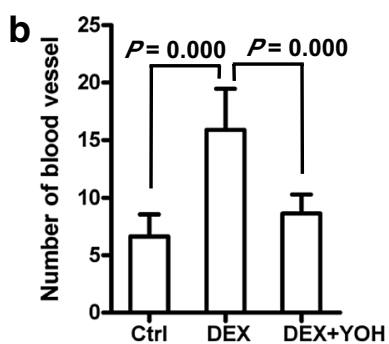

e

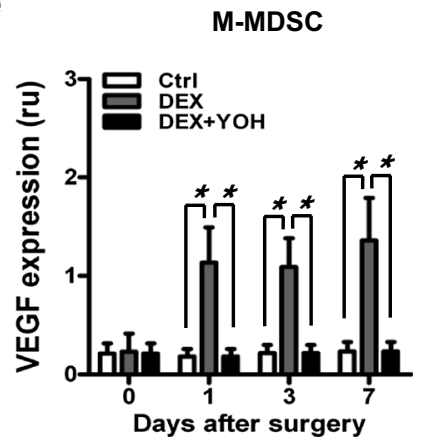

Fig. 6 DEX mediates tumour angiogenesis via VEGF. a Immunohistochemistry staining of mouse pulmonary metastatic sections with CD31 antibody. Brown lines indicate tumour blood vessels. b Tumour blood vessels were counted in ten randomly selected fields (six mice per group). c Expression of VEGF in CD11 b ${ }^{+}$Ly6C ${ }^{\text {low }}$ Ly6G $^{+}$(G-MDSC) and CD11 b ${ }^{+}$Ly6C $^{\text {high }}$ Ly6G $^{-}$(M-MDSC) cells isolated from lungs of mice was analyzed by RT-qPCR. Representative results of RT-qPCR from G-MDSC and M-MDSC isolated from lungs of mice on day 1 after surgery were shown. $\mathbf{d}$, $\mathbf{e}$ G-MDSC and M-MDSC were isolated from lungs of mice on days 0, 1, 3 and 7 after surgery and the relative mRNA expression of VEGF was analyzed by RT-qPCR (three mice per group at each point). Data presented are representative of three replicated experiments. ${ }^{*} P<0.001$. ru, relative units

Therefore, fully disclosing the mechanisms responsible for mediating the effects of surgical stress on tumour mass is crucial for determining the full effect of DEX administration on tumour metastasis and for devising effective interventions. We report that, increasing level of

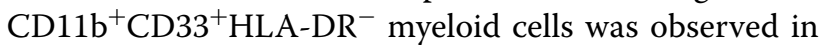
DEX-treated patients and meanwhile, these cells exhibited inhibition against $\mathrm{T}$ cell proliferation. Further characterization of the MDSC subsets that are present in lung cancer patients revealed that, while $\mathrm{CD} 14^{+}$expressing M-MDSC derived from both Ctrl and DEX-treated patients are increased, the in vitro suppressive function of M-MDSC was more potent in DEX-treated patients. Although a considerable amount of data support that DEX alleviates the inhibition of cellular immunity [27], and this immunoregulatory function are also found in tumours [28], DEX appears to exert an immunosuppressive effect in the setting of surgery. Therefore, the net effect of immunoregulatory of DEX during perioperative period could be a key factor may contribute substantially to the risk of subsequent emergence of tumour relapse and metastasis.

Another characteristic of tumor metastasis is that the formation of premetastatic niche correlates with immunosuppressive cells accumulation and subsequently formation of new blood vessels [29]. Among these immunosuppressive cells, myeloid cells such as MDSC have been proved to be a potent promoter in proangiogenesis and tumour metastasis [30]. MDSC isolated from mouse tumours displayed activated Stat3 and induced angiogenesis in an in vitro tube formation assay via Stat3 induction of angiogenic factors, including VEGF [31]. In the context of surgery, $\mathrm{CD} 11 \mathrm{~b}^{+} \mathrm{CD} 33^{+} \mathrm{HLA}^{-} \mathrm{DR}^{-}$-expressing MDSC significantly increased in lung cancer patients after thoracotomy and MDSC isolated after surgery from lung cancer patients were more efficient in promoting angiogenesis via VEGF [11]. Thus, DEX-induced MDSC may also induce formation of blood vessels and therefore promote tumour metastasis after the primary tumour removing. Our finding that high numbers of M-MDSC expanded by DEX produces high levels of VEGF sheds some mechanistic light on this issue.

The immunomodulatory properties of DEX could be beneficial in the context of inflammatory conditions that require sedation, such as sepsis, ischemia-reperfusion injury and ventilator-associated lung injury, among many others $[1,2]$. Nonetheless, in contrast to these findings, some researchers have noted that the immunomodulatory effects of DEX can be beneficial for the growth of tumours [3, 4, 32]. Takefumi et al. report that DEX 
inhibits antitumour immunity as shown by the accelerated tumour growth, possibly through the decreased production of IL-12 from antigen presenting cells, resulting in a Th2 shift and decreased cytotoxic $\mathrm{T}$ lymphocytes (CTL) activity [33]. Cata et al. retrospectively analyzed data from 1404 operated patients with non-small cell lung cancer (NSCLC), of which 241 were treated with DEX perioperatively $[34,35]$. The use of DEX was associated with statistically and clinically significant lower survival rates at 5 year postsurgery, an effect evident only in patients receiving DEX. A consensus result was observed in the present study that DEX increased the growth of metastases of a mouse lung carcinoma, and this resulted in a shorter survival time in DEX-treated mice. Whether DEX definitively enhances or inhibits tumour growth is still to be resolved, since differences in the experimental design, cancer histologic cell type, and DEX administration schedule used can all affect the experimental outcome. In clinical setting, cancer patients are exposed to DEX during surgery for removal of the primary tumour, and/or for up to a day following it [17]. Thus, the potential effects of DEX on long-term cancer outcomes would most likely be mediated through its indirect effects on a residual disease, especially on preexisting micro-metastases in the metastatic prone tissue/organ. To test whether the short-term effects of DEX on M-MDSC expansion translate to long-term effects, we applied a mouse model quantifying metastases following tumour resection. DEX increased the metastasis number in the spontaneous pulmonary experiment, indicating the biological significance of a single exposure to DEX in the context of micrometastases, and supporting the hypothesis that the effects of a relatively short perioperative exposure to DEX could have detrimental effects on long-term clinical cancer prognosis. The drug schedules of DEX employed were chosen to simulate clinical plasma levels, and behavioural and physiological effects.

Previous studies have shown that a number of immune cells functions have been altered by $\alpha_{2}-\mathrm{AR}$, but there has been no report regarding the involvement of $\alpha_{2}$-AR in the expansion of MDSC. $\alpha_{2}$-Adrenoceptors are present in $\mathrm{T}$ lymphocytes, and agonists to this receptor decrease lymphocyte proliferation and both interferon- $\gamma$ and IL-4 production [36]. DEX could reduce IL-2 production in macrophages and led to a decreased ratio of helper $\mathrm{T}$ lymphocytes subsets, Th1 to Th2 [33]. Natural killer cells also show increased cytotoxic activity in response to $\alpha_{2}$ AR agonists [37]. We may also deduce the mechanism of DEX with the expansion of M-MDSC in surgery context, since it is established that DEX can modulate the JAK/ STAT signaling pathway which may be the final transcription factor involved in the expansion of M-MDSC [38-42]. In stressed circumstances, the effects of DEX were initiated quickly following its administration, and attenuated along with cessation of its behavioural effects, suggesting immediately inducible and reversible mechanisms. Thus, immune mechanisms might include reduced antimetastatic immunity and simultaneously induced prometastatic immunity that can quickly and transiently be modulated, which controls tumor metastases.

A better understanding of immune regulatory functions of DEX, which include the mechanisms by which DEX induces immunosuppressive ingredients and promotes tumour metastasis, has a potential to lead to new avenues for preventive intervention in cancer surgery by reducing their immunosuppressive effects and preventing tumour metastasis. Most nonsteroidal anti-inflammatory drugs (NSAIDs) function as cyclooxygenase-2 (COX-2) inhibitors that inhibit production of prostaglandin E2 (PGE2) [43]. Because PGE2 induces expansion of MDSC, Fujita et al. reported that in mouse glioma model, treatment with the COX-2 inhibitors celecoxib or acetylsalicylic acid (ASA) suppress gliomagenesis by inhibiting MDSC development and accumulation in the tumor microenvironment [44]. Moreover, when applied to tumor-bearing hosts or added to MDSC cultured in a tumor microenvironment, the NSAID indomethacin (IND) induced MDSC to differentiate into a cell population with reduced suppressive activity, which favored the development of a more efficient antitumor response [45]. The possibility to modulate MDSC using NSAIDs offers an opportunity for treating a wide variety of pathologic conditions, especially cancer, without the need of depleting these cells from the host.

\section{Conclusions}

In the context of surgery, the systemic administration of DEX effectively induces the proliferation of monocytic MDSC which possess proangiogenic and immunosuppressive activity and may promote tumour metastasis. This suggests that DEX administration may exert a deleterious effect for the prognosis of lung cancer patients via modulation of premetastatic niche. Prospective randomized controlled trials are needed to properly assess the effects of DEX on lung cancer patients and other cancers, and animal studies should further elucidate potential mediating mechanisms to be tested in cancer patients.

\section{Additional files}

Additional file 1: Figure S1. Expansion of M-MDSC by dexmedetomidine is inhibited by yohimbine. (A, B) CD11 $\mathrm{b}^{+} \mathrm{CD}_{3}{ }^{+} \mathrm{HLA}$-DR ${ }^{-}$cells $\left(3 \times 10^{4}\right.$ cells/well) isolated from lung cancer patients $(n=6) 24 \mathrm{~h}$ after surgery were cocultured with $\mathbf{( A )}$ dexmedetomidine (DEX) or (B) dexmedetomidine and yohimbine (DEX $+\mathrm{YOH})$. Twenty-four hours after coculture, 
floating cells were collected and numerated using an automated cell counter. The percentage of $\mathrm{CD} 11 \mathrm{~b}^{+} \mathrm{CD} 33^{+} \mathrm{HLA}-\mathrm{DR}{ }^{-} \mathrm{CD} 14^{+}$(M-MDSC) was analyzed by flow cytometry and the absolute number of M-MDSC was calculated.

Additional file 2: Figure S2. DEX promotes tumour metastases in mice exposed to tumour excision. $1 \times 10^{6} \mathrm{LLC}$ cells were injected s.c. into the dorsa of C57BL/6 mice. When tumors were $1500 \mathrm{~mm}^{3}$ in size, the mice were divided into 3 groups and treated with PBS (Ctrl group), dexmedetomidine (DEX group), or dexmedetomidine and yohimbine ( $\mathrm{DEX}+\mathrm{YOH}$ group). Then the mice immediately underwent surgical removal of the tumor. (A) When the mice showed dyspnea, they were euthanized and their lungs were removed. (B) On day 60 after tumor resection, the survived mice from $\mathrm{Ctrl}$ and $\mathrm{DEX}+\mathrm{YOH}$ group were euthanized and their lungs were removed.

Additional file 3: Figure S3. Expression of $a_{2}-A R$ on mouse MDSC. LLC cells were injected s.c. into the dorsa of C57BL/ 6 mice. When tumours were $1500 \mathrm{~mm}^{3}$ in size, the mice were divided into 3 groups and treated with PBS (Ctrl), DEX or DEX and YOH (DEX + YOH). Then the mice immediately underwent surgical removal of the tumor. Expression of $\mathrm{a}_{2}$-AR was analyzed on days $0,1,3$ and 7 (depicted as $T_{0}, T_{1}, T_{2}$ and $T_{3}$ ) after surgery

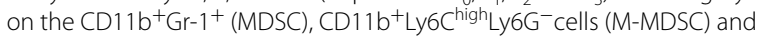
$\mathrm{CD} 11 \mathrm{~b}^{+} \mathrm{Ly} 6 \mathrm{C}^{\text {low }} \mathrm{Ly} 6 \mathrm{G}^{+}$(G-MDSC) of lungs of mice (three mice per group at each time point) by flow cytometry. Mean fluorescent intensity (MFI) of $\mathrm{a}_{2}$-AR on (A) MDSC, (B) M-MDSC and (C) G-MDSC was assessed. ${ }^{*} P<0.001$ as compared with $\mathrm{T}_{0}$ in Ctrl group; ${ }^{P} P<0.001$ as compared with $\mathrm{T}_{0}$ in $\mathrm{DEX}$ group; ${ }^{\dagger} P<0.001$ as compared with $\mathrm{T}_{0}$ in $\mathrm{DEX}+\mathrm{YOH}$ group.

\section{Abbreviations}

$a_{2}-A R: a_{2}$-adrenergic receptor; DEX: dexmedetomidine; ELISA: enzyme-linked immunosorbent assay; FACS: fluorescence-activated cell sorting; FCM: flow cytometry; IL: interleukin; MDSC: myeloid-derived suppressor cells; MFI: mean fluorescence intensity; PBMC: peripheral blood mononuclear cells; PBS: phosphate-buffered saline; RT-qPCR: reverse-transcription quantitative polymerase chain reaction; VEGF: vascular epithelial growth factor; YOH: yohimbine.

\section{Authors' contributions}

XSS: conception and design, financial support, administrative support, data analysis and interpretation, manuscript writing, final approval of manuscript; YDF, LY, JH, FQ, and YF: collection and/or assembly of data, data analysis and interpretation, final approval of manuscript; JW: conception and design, data analysis and interpretation, manuscript writing, financial support. All authors read and approved the final manuscript.

\section{Author details}

${ }^{1}$ Biomedical Research Center, Affiliated Calmette Hospital of Kunming Medical University, 504 Qing Nian Road, Kunming 650011, Yunnan, People's Republic of China. ${ }^{2}$ Department of Neurosurgery, Third Affiliated Hospital of Kunming Medical University (Yunnan Cancer Hospital), 519 Kun Zhou Road, Kunming 650118, Yunnan, People's Republic of China. ${ }^{3}$ Department of Anesthesiology, First Affiliated Hospital of Kunming Medical University, 295 Xi Chang Road, Kunming 650032, Yunnan, People's Republic of China.

\section{Acknowledgements}

Not applicable.

\section{Competing interests}

The authors declare that they have no competing interests.

\section{Availability of data and materials}

All data and materials are available in this published article.

\section{Consent for publication}

Not applicable.

\section{Ethics approval and consent to participate}

This research was in compliance with the Helsinki Declaration and approved by the ethics committee of the Kunming Medical University, Kunming, China (Protocol Identification: 2014-A105/06). Informed written consent was obtained from all participants. All animal experiments were performed according to the guidelines and protocols approved by the Institutional Animal Care and Use Committee at the Kunming Medical University (V0013-017.06.001).

\section{Funding}

This study was supported by the National Nature Science Foundation of China (NSFC, Grant Numbers 31660257, 81760519 and 31360223).

\section{Publisher's Note}

Springer Nature remains neutral with regard to jurisdictional claims in published maps and institutional affiliations.

\section{Received: 17 September 2018 Accepted: 5 December 2018}

Published online: 11 December 2018

\section{References}

1. Farag E, Argalious M, Abd-Elsayed A, Ebrahim Z, Doyle DJ. The use of dexmedetomidine in anesthesia and intensive care: a review. Curr Pharm Des. 2012;18:6257-65.

2. Mantz J, Josserand J, Hamada S. Dexmedetomidine: new insights. Eur J Anaesthesiol. 2011;28:3-6.

3. Bruzzone $A$, Piñero $C P$, Rojas $P$, Romanato $M$, Gass $H$, Lanari C, Lüthy IA. a(2)-Adrenoceptors enhance cell proliferation and mammary tumor growth acting through both the stroma and the tumor cells. Curr Cancer Drug Targets. 2011;11:763-74.

4. Bruzzone A, Piñero CP, Castillo LF, Sarappa MG, Rojas P, Lanari C, Lüthy IA. Alpha2-adrenoceptor action on cell proliferation and mammary tumour growth in mice. Br J Pharmacol. 2008;155:494-504.

5. Lavon H, Matzner P, Benbenishty A, Sorski L, Rossene E, Haldar R, Elbaz E, Cata JP, Gottumukkala V, Ben-Eliyahu S. Dexmedetomidine promotes metastasis in rodent models of breast, lung, and colon cancers. $\mathrm{Br} J$ Anaesth. 2018;120:188-96.

6. Veglia F, Perego M, Gabrilovich DI. Myeloid-derived suppressor cells coming of age. Nat Immunol. 2018;19:108-19.

7. Youn Jl, Gabrilovich DI. The biology of myeloid-derived suppressor cells: the blessing and the curse of morphological and functional heterogeneity. Eur J Immunol. 2010;40:2969-75.

8. Youn JI, Nagaraj S, Collazo M, Gabrilovich DI. Subsets of myeloid-derived suppressor cells in tumor-bearing mice. J Immunol. 2008;181:5791-802.

9. Movahedi K, Guilliams M, Van den Bossche J, Van den Bergh R, Gysemans C, Beschin A, De Baetselier P, Van Ginderachter JA. Identification of discrete tumor-induced myeloid-derived suppressor cell subpopulations with distinct T cell-suppressive activity. Blood. 2008;111:4233-44.

10. Condamine T, Ramachandran I, Youn JI, Gabrilovich DI. Regulation of tumor metastasis by myeloid-derived suppressor cells. Annu Rev Med. 2015;66:97-110.

11. Wang J, Su XS, Yang L, Qiao F, Fang Y, Yu L, Yang Q, Wang YY, Yin YF, Chen R, Hong ZP. The influence of myeloid-derived suppressor cells on angiogenesis and tumor growth after cancer surgery. Int J Cancer. 2016;138:2688-99.

12. Wang J, Yang L, Yu L, Wang YY, Chen R, Qian J, Hong ZP, Su XS. Surgeryinduced monocytic myeloid-derived suppressor cells expand regulatory T cells in lung cancer. Oncotarget. 2017;8:17050-8.

13. Horowitz M, Neeman E, Sharon E, Ben-Eliyahu S. Exploiting the critical perioperative period to improve long-term cancer outcomes. Nat Rev Clin Oncol. 2015;12:213-26.

14. O'Reilly MS, Holmgren L, Shing Y, Chen C, Rosenthal RA, Moses M, Lane WS, Cao Y, Sage EH, Folkman J. Angiostatin: a novel angiogenesis inhibitor that mediates the suppression of metastases by a Lewis lung carcinoma. Cell. 1994;79:315-28.

15. Gabrilovich DI, Nagaraj S. Myeloid-derived suppressor cells as regulators of the immune system. Nat Rev Immunol. 2009;9:162-74.

16. Yang L, DeBusk LM, Fukuda K, Fingleton B, Green-Jarvis B, Shyr Y, Matrisian LM, Carbone DP, Lin PC. Expansion of myeloid immune suppressor $\mathrm{Gr}+\mathrm{CD} 11 \mathrm{~b}+$ cells in tumor-bearing host directly promotes tumor angiogenesis. Cancer Cell. 2004;6:409-21. 
17. Ramadhyani U, Park JL, Carollo DS, Waterman RS, Nossaman BD. Dexmedetomidine: clinical application as an adjunct for intravenous regional anesthesia. Anesthesiol Clin. 2010;28:709-22.

18. O'Dwyer MJ, Owen HC, Torrance HD. The perioperative immune response. Curr Opin Crit Care. 2015;21:336-42.

19. Goldfarb Y, Sorski L, Benish M, Levi B, Melamed R, Ben-Eliyahu S. Improving postoperative immune status and resistance to cancer metastasis: a combined perioperative approach of immunostimulation and prevention of excessive surgical stress responses. Ann Surg. 2011;253:798-810.

20. Tsuchiya Y, Sawada S, Yoshioka I, Ohashi Y, Matsuo M, Harimaya Y, Tsukada K, Saiki I. Increased surgical stress promotes tumor metastasis. Surgery. 2003;133:547-55.

21. Camara-Lemarroy CR, Rendon-Ramirez EJ, Ibarra-Yruegas BE. Immunomodulatory effects of dexmedetomidine: from bench to clinic. World J Anesth. 2014;2:137-45.

22. Wang Y, Xu X, Liu H, Ji F. Effects of dexmedetomidine on patients undergoing radical gastrectomy. J Surg Res. 2015;194:147-53.

23. Lamkin DM, Sung HY, Yang GS, David JM, Ma JC, Cole SW, Sloan EK. a2-Adrenergic blockade mimics the enhancing effect of chronic stress on breast cancer progression. Psychoneuroendocrinology. 2015;51:262-70.

24. Yang XH, Bai Q, Lv MM, Fu HG, Dong TL, Zhou Z. Effect of dexmedetomidine on immune function of patients undergoing radical mastectomy: a double blind and placebo control study. Eur Rev Med Pharmacol Sci. 2017:21:1112-6.

25. Wang K, Li C. Effects of dexmedetomidine on inflammatory factors, T lymphocyte subsets and expression of NF-KB in peripheral blood mononuclear cells in patients receiving radical surgery of colon carcinoma. Oncol Lett. 2018;15:7153-7.

26. Giles AJ, Reid CM, Evans JD, Murgai M, Vicioso Y, Highfill SL, Kasai M, Vahdat L, Mackall CL, Lyden D, Wexler L, Kaplan RN. Activation of hematopoietic stem/progenitor cells promotes immunosuppression within the pre-metastatic niche. Cancer Res. 2016;76:1335-47.

27. Kim Y, Kang SH, Hong TH, Cho ML, Han HJ, Kwon SJ, Lee J. Effects of dexmedetomidine on the ratio of T helper 1 to T helper 2 cytokines in patients undergoing laparoscopic cholecystectomy. J Clin Anesth. 2014;26:281-5

28. Wu L, Lv H, Luo W, Jin S, Hang Y. Effects of dexmedetomidine on cellular immunity of perioperative period in children with brain neoplasms. Int Clin Exp Med. 2015;8:2748-53.

29. Belizon A, Balik E, Feingold DL, Bessler M, Arnell TD, Forde KA, Horst PK, Jain S, Cekic V, Kirman I, Whelan RL. Major abdominal surgery increases plasma levels of vascular endothelial growth factor: open more so than minimally invasive methods. Ann Surg. 2006;244:792-8.

30. Murdoch C, Muthana M, Coffelt SB, Lewis CE. The role of myeloid cells in the promotion of tumour angiogenesis. Nat Rev Cancer. 2008;8:618-31.

31. Yang L, DeBusk LM, Fukuda K, Fingleton B, Green-Jarvis B, Shyr Y, Matrisian LM, Carbone DP, Lin PC. Expansion of myeloid immune suppressor $\mathrm{Gr}+\mathrm{CD} 11 \mathrm{~b}+$ cells in tumor-bearing host directly promotes tumor angiogenesis. Cancer Cell. 2004;6:409-21.
32. Szpunar MJ, Burke KA, Dawes RP, Brown EB, Madden KS. The antidepressant desipramine and a2-adrenergic receptor activation promote breast tumor progression in association with altered collagen structure. Cancer Prev Res (Phila). 2013;6:1262-72.

33. Inada T, Shirane A, Hamano N, Yamada M, Kambara T, Shingu K. Effect of subhypnotic doses of dexmedetomidine on antitumor immunity in mice. Immunopharmacol Immunotoxicol. 2005;27:3573.

34. Cata JP, Singh V, Lee BM, Villarreal J, Mehran JR, Yu J, Gottumukkala $V$, Lavon $H$, Ben-Eliyahu S. Intraoperative use of dexmedetomidine is associated with decreased overall survival after lung cancer surgery. J Anaesthesiol Clin Pharmacol. 2017;33:317-23.

35. Lavon H, Krigman R, Elbaz E, Sorski L, Matzner P, Shaashua L, Benbenishty A, Cata J, Gottumukkala V, Ben-Eliyahu S. The perioperative use of the sedative dexmedetomidine in cancer patients may have detrimental effects. Brain Behav Immun. 2015;49:e29.

36. Bao JY, Huang Y, Wang F, Peng YP, Qiu YH. Expression of alpha-AR subtypes in T lymphocytes and role of the alphaARs in mediating modulation of T cell function. Neuro Immuno Modulation. 2007:14:344-53.

37. Xiao J, Huang HW, Peng YP, Bao JY, Huang Y, Qiu YH. Modulation of natural killer cell function by alpha-adrenoreceptor-coupled signalling. Neuro Endocrinol Lett. 2010;31:635-44.

38. Si Y, Bao H, Han L, Shi H, Zhang Y, Xu L, Liu C, Wang J, Yang X, Vohra A, Ma D. Dexmedetomidine protects against renal ischemia and reperfusion injury by inhibiting the JAK/STAT signaling activation. J TransI Med. 2013;11:141.

39. Yu H, Liu Y, McFarland BC, Deshane JS, Hurst DR, Ponnazhagan S, Benveniste EN, Qin H. SOCS3 deficiency in myeloid cells promotes tumor development: involvement of STAT3 activation and myeloid-derived suppressor cells. Cancer Immunol Res. 2015;3:727-40.

40. Yan D, Yang Q, Shi M, Zhong L, Wu C, Meng T, Yin H, Zhou J. Polyunsaturated fatty acids promote the expansion of myeloid-derived suppressor cells by activating the JAK/STAT3 pathway. Eur J Immunol. 2013;43:2943-55.

41. Condamine T, Mastio J, Gabrilovich DI. Transcriptional regulation of myeloid-derived suppressor cells. J Leukoc Biol. 2015:98:913-22.

42. Nefedova Y, Huang M, Kusmartsev S, Bhattacharya R, Cheng P, Salup R, Jove R, Gabrilovich DI. Hyperactivation of STAT3 is involved in abnormal differentiation of dendritic cells in cancer. J Immunol. 2004;172:464-74.

43. Sinha P, Clements VK, Fulton AM, Ostrand-Rosenberg S. Prostaglandin E2 promotes tumor progression by inducing myeloid-derived suppressor cells. Cancer Res. 2007;67:4507-13.

44. Fujita M, Kohanbash G, Fellows-Mayle W, Hamilton RL, Komohara Y, Decker SA, Ohlfest JR, Okada H. COX-2 blockade suppresses gliomagenesis by inhibiting myeloid-derived suppressor cells. Cancer Res. 2011;71:2664-74

45. Obermajer N, Muthuswamy R, Lesnock J, Edwards RP, Kalinski P. Positive feedback between PGE2 and COX2 redirects the differentiation of human dendritic cells toward stable myeloid-derived suppressor cells. Blood. 2011;118:5498-505.

\footnotetext{
Ready to submit your research? Choose BMC and benefit from:

- fast, convenient online submission

- thorough peer review by experienced researchers in your field

- rapid publication on acceptance

- support for research data, including large and complex data types

- gold Open Access which fosters wider collaboration and increased citations

- maximum visibility for your research: over $100 \mathrm{M}$ website views per year
}

At BMC, research is always in progress.

Learn more biomedcentral.com/submissions 